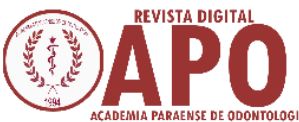

\title{
Efeito in vitro da arginina em diferentes concentrações após clareamento dental
}

\section{In vitro effect of different arginine concentrations after tooth bleaching}

\author{
Beatriz Helena Rodrigues Silva ${ }^{1}$ \\ Fabiana Brito da Cunha ${ }^{2}$ \\ Brenda Lucy Freitas De Paula ${ }^{3}$ \\ Cristiane de Melo Alencar ${ }^{3}$ \\ Yasmin do Socorro Batista Gomes ${ }^{1}$ \\ Cecy Martins Silva ${ }^{4}$
}

\section{RESUMO}

Este estudo visa comparar in vitro, o efeito de dentifrícios contendo diferentes concentrações de arginina, aplicados sobre o esmalte clareado com peróxido de hidrogênio (PH) a 35\%, na dureza Vickers (VHN), rugosidade (Ra) e colorimetria triistimulus $(\mathrm{CT})$. Quarenta e cinco espécimes obtidos a partir de terceiros molares humanos recém-extraídos foram divididos em três grupos: grupo controle $(\mathrm{n}=15)$ grupo arginina $8 \%(\mathrm{n}=15)$ e grupo arginina $12 \%(\mathrm{n}=5)$. Os espécimes receberam tratamento clareador com $\mathrm{PH}$ a $35 \%$. Após o clareamento, os grupos experimentais receberam a aplicação de dentifrício à base de arginina, a 8\% ou $12 \%$, por 5 minutos. A análise estatística foi realizada com teste ANOVA, com pós-teste de Tukey. Comparado ao controle, o tratamento com arginina aumentou $(\mathrm{p}<0,05)$ a VHN e diminuiu $(\mathrm{p}<0,05)$ o Ra, no entanto a concentração de arginina, $8 \%$ e $12 \%$, não influenciou os resultados de VHN (p > 0,05) e Ra $(\mathrm{p}>0,05)$. O tratamento ou concentração de arginina não influenciaram em CT $(\mathrm{p}=0,81)$. Conclui-se que ambas as concentrações do aminoácido arginina são semelhantemente eficazes em tratar os efeitos deletérios associados ao clareamento dentário, sem interferir na alteração de cor.

Palavras chave: Clareamento dental. Arginina. Materiais dentários.

\begin{abstract}
The objective of the experiment was to compare in vitro the effect of dentifrices containing different concentrations of arginine applied on the enamel bleached with hydrogen peroxide (HP) at $35 \%$ in Vickers hardness (VHN), roughness (Ra) and Triistimulus colorimetry (CT). Forty-five specimens obtained from newly extracted human third molars were divided into three groups: control $(n=15)$ arginine $8 \%(n=15)$ and arginine 12\% $(\mathrm{n}=5)$. Specimens received 35\% HP bleaching treatment. After bleaching, the arginine groups received application of arginine dentifrice at $8 \%$ or $12 \%$ for 5 minutes. Statistical analysis was performed using the ANOVA test, with Tukey post-test. Compared with control, arginine treatment increased $(\mathrm{p}<0.05)$ the VHN and decreased $(\mathrm{p}<0.05)$ the Ra. Arginine concentration, $8 \%$ and $12 \%$, however, did not influence VHN $(\mathrm{p}>0.05)$ and $\mathrm{Ra}(\mathrm{p}>0.05)$. Treatment or arginine concentration did not influence CT $(\mathrm{p}=0.81)$. In conclusion, 8 or $12 \%$ concentrations of the amino acid arginine are similarly effective in treating deleterious effects associated with tooth bleaching without interfering with color change.
\end{abstract}

Keyword: Tooth bleaching. Arginine. Dental materials.

\footnotetext{
${ }^{1}$ Graduando(a), Faculdade de Odontologia,Universidade Federal do Pará

${ }^{2}$ Cirurgiã-dentista

${ }^{3}$ Pós-graduanda (a), Faculdade de Odontologia, Universidade Federal do Pará

${ }^{4}$ Professor(a) Doutor(a), Faculdade de Odontologia, Universidade Federal do Pará
} 


\section{INTRODUÇÃo}

A cor dos dentes é determinada por propriedades óticas de tecidos mineralizados e efeitos combinados de pigmentação extrínseca e intrínseca. ${ }^{1,2} \mathrm{O}$ escurecimento dentário intrínseco é geralmente causado pela idade e necrose pulpar, enquanto a maioria das causas extrínsecas são café, chá, vinho tinto e tabaco ${ }^{1,3}$. O clareamento dentário, dentre os tratamentos disponíveis para a otimização da estética dentária, é considerado como a técnica menos invasiva ${ }^{4}$.

O peróxido de hidrogênio é um agente oxidante que ao interagir com moléculas pigmentadas, provoca a redução de seu tamanho a um nível tal que permite sua remoção da estrutura dentária através do processo de difusão, o que indiretamente promove a redução da absorção de luz, tornando o dente mais claro ${ }^{5}$.

O clareamento de consultório utilizando peróxido de hidrogênio foi introduzido em $1918^{6}$. Altas taxas de sucesso têm sido demonstradas em técnicas clareadoras com peróxido de hidrogênio a $35 \%{ }^{7}$, e oferece resultados mais imediatos em relação ao caseiro ${ }^{8,9}$. Muitos estudos têm mostrado que os agentes clareadores podem ter impactos significativos na morfologia superficial, composição química, microdureza e até mesmo na resistência à fratura de superfícies dentárias ${ }^{10,11,12}$.

A morfologia do esmalte dentário influencia na quantidade e tipo de reflexão da luz. Uma superfície rugosa ou grosseira resulta em uma reflexão mais difusa, enquanto uma superfície lisa leva à uma reflexão mais especular ${ }^{1}$. Dessa forma, o clareamento dentário não é apenas relacionado aos efeitos dos cromóforos, mas também com as mudanças nas propriedades óticas do esmalte $^{6}$. Portanto, o tratamento de alterações morfológicas do esmalte é de significativa importância para a eficácia do branqueamento.

As alterações morfológicas do esmalte clareado também podem resultar em consequências clínicas mais subjetivas, como a sensibilidade dentária, a qual é o resultado de uma injúria pulpar, gerada pela rápida difusão de moléculas de peróxido de hidrogênio $(\mathrm{PH})$ nos tecidos dentários ${ }^{13}$, o que pode ocasionar um decréscimo de celularidade e metabolismo celular ${ }^{14}$, podendo levar inclusive à necrose tecidual ${ }^{15,16,17}$. As moléculas de PH liberam espécies reativas de oxigênio, tais como ânions superóxidos $\left(\mathrm{O}^{2-}\right), \mathrm{H}_{2} \mathrm{O}_{2}$, radicais hidroxila $\left(\mathrm{OH}^{-}\right)$e $\mathrm{O}_{2}$, e estas são capazes de induzir estresse oxidativo que se caracteriza pelo desequilíbrio entre a quantidade de espécies reativas de oxigênio e a quantidade de antioxidantes endógenos ou exógenos ${ }^{18}$.

Diferentes métodos vêm sendo empregados com o objetivo de eliminar ou amenizar os efeitos deletérios provenientes do clareamento dental, como o uso de dentifrícios contendo agentes remineralizantes. A arginina é um aminoácido naturalmente presente na saliva e atua como uma barreira física à penetração do peróxido de hidrogênio devido sua ação de oclusão dos túbulos dentinários abertos ${ }^{19}$, através da formação de precipitados na superfície dentinária e no interior desses túbulos ${ }^{20}$. Estudos anteriores têm demonstrado que o composto arginina $(8 \%)$ + carbonato de cálcio é um sistema remineralizante altamente efetivo ${ }^{19,21}$.

Conhecendo-se então os efeitos benéficos do aminoácido arginina em uma concentração de 8\%, surgem questionamentos acerca da possibilidade de que um aumento na concentração de arginina possa representar uma otimização dos efeitos deste bioativo. Portanto, este estudo visa comparar, in vitro, o efeito de dentifrícios contendo diferentes concentrações de arginina ( $8 \%$ e $12 \%$ ) associadas ao carbonato de cálcio $40 \%$, aplicados sobre o esmalte clareado com peróxido de hidrogênio em alta concentração (35\%) na dureza, rugosidade e alteração de cor. As seguintes hipóteses nulas foram testadas: $H_{01}$ : não há diferenças estatisticamente significativas na microdureza Vickers do esmalte entre os grupos experimentais; $\mathrm{H}_{02}$ : não há diferenças estatisticamente significativas na rugosidade superficial do esmalte entre os grupos experimentais; $\mathrm{H}_{03}$ : a aplicação de arginina não interfere na eficácia do clareamento.

\section{Metodologia}

O estudo foi aprovado pelo Comitê de Ética em Pesquisa do ICS da Universidade Federal do Pará, Brasil, sob o número 2.102.160.

\section{Seleção e Armazenamento dos Dentes}

Os dentes utilizados nesta pesquisa foram doados por pacientes após assinatura de um termo de consentimento. Foram utilizados 45 terceiros molares 
humanos recém extraídos, totalmente inclusos, isentos de trincas ou manchas. Os dentes foram limpos com curetas de Gracey para a remoção de tecidos remanescentes e depois passaram por profilaxia com escova de Robson e pasta profilática, para obter total remoção do material orgânico e inorgânico aderido à superfície coronária, visando uma superfície limpa. Cada dente foi seccionado transversalmente no limite coroa/raiz, no limite da junção amelocementária. As coroas foram selecionadas para o experimento e armazenados em água destilada até o início do preparo dos espécimes.

\section{Preparo dos Espécimes}

As superfícies vestibulares foram cortadas com um disco de dupla face (KG Sorensen, modelo 18002,7020, Cotia, SP, BR) acoplados a um micromotor de baixa velocidade, sob refrigeração com água corrente para evitar a queima do tecido dental, e regularizadas com pontas diamantadas $n^{\circ} 4138$ (KG Sorensen ${ }^{\circledR}$ ), formando 45 fragmentos com dimensões de $3 \times 3 \times 3 \mathrm{~mm}$. A porção recortada sempre correspondeu à zona central da superfície vestibular da coroa dentária, de modo a obter prismas de esmalte com as mesmas inclinações. As superfícies dos espécimes foram aplainadas com lixas d'água de granulações 600, 1200 e 2000, sucessivamente, sob água corrente, realizando-se em seguida, o polimento do esmalte em uma politriz APL-4 (Arotec Ltda, São Paulo, SP, BR) dotada de disco de feltro, associada a uma pasta de alumínio (Alpha Micropolisha10 - Union Carbide, Greensburg, LA).

\section{Grupos experimentais}

A tabela 1 mostra a divisão dos espécimes em 3 grupos $(n=15)$ : grupo controle, apenas clareado com peróxido de hidrogênio a 35\% (White and Brite Advanced, 3M/ESPE, Sumaré, SP, BR); grupo arginina $8 \%$ e grupo arginina $12 \%$, os quais, receberam aplicação tópica de dentifrício à base de arginina (carbonato de cálcio 40\%; sorbitol 20\%; laurilsulfato de sódio 1,2\%; carboximetilcelulose $2 \%$; goma xantana $1 \%$; sacarina sódica $0,1 \%$; flavorizante de menta $0,75 \%$; $\mathrm{L}$ arginina $8 \%$ ou $12 \%$; solução aquosa em quantidade suficiente (QSP). Farmácia de manipulação ApisMell, Belém, PA,
BR) durante 5 minutos após o término de cada sessão clareadora. Cinco espécimes de cada grupo experimental foram submetidos aos testes de VHN e CT. Dez (10) espécimes de cada grupo foram submetidos aos ensaios de Ra. Todas as análises foram realizadas antes e após o tratamento clareador.

Tabela 1. Divisão dos grupos experimentais.

\begin{tabular}{lll}
\hline Grupos & Tratamento & $\begin{array}{l}\text { Métodos } \\
\text { Experimentais }\end{array}$
\end{tabular}

\begin{tabular}{l|l|l}
\hline Controle & $\begin{array}{l}\text { Clareamento } \\
\text { Dentário }\end{array}$ & \multirow{2}{*}{} \\
\cline { 1 - 2 } Arginina 8\% & $\begin{array}{l}\text { Clareamento } \\
\text { Dentário + } \\
\text { Aplicação de } \\
\text { arginina a 8\% }\end{array}$ & VHN \\
& CT \\
& Ra \\
\hline Arginina & Clareamento & \\
$\mathbf{1 2 \%}$ & Dentário + & \\
& Aplicação de & \\
& arginina a12\% & \\
\hline
\end{tabular}

Fonte: Autores da pesquisa, 2017

A aplicação do agente clareador seguiu as recomendações do fabricante. Foram realizadas 3 sessões de 45 minutos com um intervalo de 7 dias. Em cada sessão, três aplicações foram efetuadas no esmalte durante 15 minutos. Após cada sessão de clareamento, as amostras foram lavadas em água corrente. As superfícies receberam polimento superficial com roda de feltro e pasta de polimento (Diamond Excel - FGM Produtos odontológicos, Joinville, SC, BR) acoplada em peça de mão de baixa rotação (Contra-ângulo redutor ROC 16:1 - Dabi Atlante, Ribeirão Preto, SP, BR). Os grupos arginina $8 \%$ e arginina $12 \%$ receberam aplicação tópica dos respectivos dentifrícios durante 5 minutos após o polimento de cada sessão de tratamento. Os espécimes foram armazenados em saliva artificial, (500 $\mathrm{mL}$ - cloreto de potássio, cloreto de sódio, cloreto de magnésio, fosfato de potássio, cloreto de cálcio, Conservantes, carboximetilcelulose, sorbitol; solução aquosa QSP (Farmácia ApisMell ${ }^{\circledR}$ ), a qual foi renovada diariamente e mantidos em uma estufa biológica a $37^{\circ} \mathrm{C}$ 
(Q316M2 - 1’3/288 V - 188W, Quimis Aparelhos Científicos Ltda, São Paulo, SP, BR).

\section{Métodos experimentais}

\section{Microdureza Vickers}

Cinco espécimes de cada grupo foram testados quanto à VHN. Cinco edentações, separadas por 100 $\mu \mathrm{m}$, foram feitas em cada amostra, utilizando uma carga de 25 gf durante 5 segundos em um microdurômetro (HMV - Shimadzu, São Paulo, SP, BR). A lente ocular utilizada correspondeu ao aumento de 10x e a objetiva de 40x, apresentando, portanto, uma magnificação total de 400x. Penetrações foram feitas de modo que foi possível mapear hipoteticamente a área total dos corpos de prova (extremidade central, lateral esquerda, lateral direita, extremidade superior e extremidade inferior). As análises de VHN foram realizadas antes (inicial) e imediatamente após o tratamento (final) de branqueamento. A percentagem de alteração em VHN (VHN\%) foi calculada como:

$$
\% V H N=\left[\frac{(\text { VHN Final }- \text { VHN Inicial })}{\text { VHN Inicial }}\right] \times 100 \%
$$

\section{Rugosidade superficial}

Dez amostras de cada grupo foram utilizadas para os testes de rugosidade. Um rugosímetro (Mitutoyo SJ-210 Surftest 178-560-01D - Mitutoyo Sul América, Santo Amaro, SP, BR) foi utilizado para medir os parâmetros de $\mathrm{Ra}$ (rugosidade média) antes e após os procedimentos de clareamento. O ponto do rugosímetro percorreu $4 \mathrm{~mm}$ diagonalmente em cada corpo de prova e forneceu o resultado da medição da rugosidade desse trajeto. Foram feitas 3 medições diametralmente opostas. Obteve-se a $\mathrm{Ra}$ superficial a partir de um programa do próprio aparelho, o qual foi previamente estabelecido e calibrado. As alterações anatômicas superficiais da peça (plano ou convexo) foram desta forma, compensadas pelo programa, não afetando os resultados da rugosidade. A rugosidade média foi obtida pela média aritmética da somatória dos valores absolutos dos desvios do perfil da superfície a partir da linha central dentro do traçado avaliado. A variação percentual na Ra superficial (\% RaS) foi calculada para cada grupo de acordo com a seguinte fórmula:

$$
\% \text { RaS }=\left[\frac{(\text { RaS Final-RaS Inicial })}{\text { RaS Inicial }}\right] \times 100 \%
$$

\section{Colorimetria triistimulus}

A cor dos espécimes foi aferida com auxílio de um colorímetro (CR-400 - Colorímetro Konica Minolta Tecnal Ind., Piracicaba, SP, BR) usando o sistema CIE $L^{*} a^{*} b^{*}$. Os espécimes foram colocados sobre uma superfície preta de modo que a luz refletida não interferisse nos valores de cor dos espécimes. Para avaliar a alteração de cor $(\Delta \mathrm{E})$ entre os resultados iniciais e finais, $\Delta \mathrm{E}$ foi calculado usando a seguinte fórmula: $\Delta E=\left\{\Delta E(\Delta L)^{2}+(\Delta a)^{2}+(\Delta b)^{2}\right\}^{1 / 2}$, onde $\Delta \mathrm{L}=\mathrm{L}-\mathrm{L} 0, \Delta \mathrm{a}=\mathrm{a}-\mathrm{a} 0, \mathrm{e} \Delta \mathrm{b}=\mathrm{b}-\mathrm{b} 0 . \Delta \mathrm{L}, \Delta \mathrm{a}$ e $\Delta \mathrm{b}$ representam a variação das coordenadas em pretobranco, verde-vermelho e amarelo-azul, respectivamente.

\section{Análise estatística}

Para a verificação da distribuição da normalidade dos dados utilizou-se o teste Shapiro-Wilk. Todos os testes foram calculados a um nível de significância de 5\%. Para análise estatística da variação de VHN, Ra e CT utilizou-se o teste ANOVA. A análise de variância foi complementada, quando necessário, pelo teste pós-hoc de Tukey.

\section{Resultados}

\section{Análise da Microdureza Vickers (VHN)}

$\mathrm{Na}$ avaliação intragrupo foi observada diferença estatística nos diferentes tempos de avaliação, entre todos os grupos $(\mathrm{p}=0,0001)$. Na avaliação intergrupo houve diferença estatisticamente significante $(\mathrm{p}<0,05)$ entre os grupos Arginina em concentração a $8 \%$ e $12 \%$, quando comparados ao grupo controle na avaliação final de VHN. Os resultados dos diferentes períodos de avaliação estão expressos na tabela 2 . 
Tabela 2. Médias ( \pm desvio padrão) dos valores de VHN nos diferentes grupos $(n=5)$. Teste ANOVA com pós teste Tukey.

Valores de $\mathrm{VHN}$

\begin{tabular}{lcc}
\hline \multicolumn{1}{c}{ GRUPOS } & INICIAL $^{c}$ & FINAL \\
\hline Controle & $362.48( \pm 7.56)^{\mathrm{Aa}}$ & $290.36( \pm 3.7)^{\mathrm{Bb}}$ \\
Arginina 8\% $^{\mathrm{C}}$ & $361.88( \pm 6.00)^{\mathrm{Aa}}$ & $535.12( \pm 4.13)^{\mathrm{Cb}}$ \\
Arginina 12\% $^{\mathrm{Aa}}$ & $361.92( \pm 6.79)^{\mathrm{Aa}}$ & $545.84( \pm 4.56)^{\mathrm{Cb}}$ \\
\hline
\end{tabular}

Fonte: Autores da pesquisa, 2017

*Letras maiúsculas diferentes representam diferença estatística intergrupo para os diferentes tempos de avaliação, $p \leq 0.05$.

${ }^{*}$ Letras minúsculas diferentes representam diferença estatística intragrupo para os diferentes tempos de avaliação, $p \leq 0.05$

\section{Análise de Rugosidade (Ra)}

$\mathrm{Na}$ avaliação intragrupo, observou-se diferença estatística nos diferentes tempos de avaliação $(\mathrm{p}=0,0001)$ para todos os grupos. A análise intergrupo mostrou diferença estatisticamente significante $(p<0,05)$ entre os grupos Arginina em concentração a $8 \%$ e $12 \%$ quando comparados ao grupo controle na análise final de rugosidade. Resultados expressos na tabela 2.

Tabela 3. Médias ( \pm desvio padrão) dos valores rugosidade (Ra) dos diferentes grupos $(n=5)$. Teste ANOVA com pósteste Tukey.

Valores de Rugosidade (Ra)

\begin{tabular}{ccc}
\hline GRUPOS & INICIAL & FINAL \\
\hline Controle & $0.138( \pm 0.02)^{\mathrm{Aa}}$ & $0.156( \pm 0.02)^{\mathrm{Bb}}$ \\
$\begin{array}{c}\text { Arginina 8\% } \\
\text { Arginina } \\
\mathbf{1 2 \%}\end{array}$ & $0.138( \pm 0.02)^{\mathrm{Aa}}$ & $0.091( \pm 0.00)^{\mathrm{Cb}}$ \\
\hline
\end{tabular}

Fonte: Autores da pesquisa, 2017

*Letras maiúsculas diferentes representam diferença estatística intergrupo para os diferentes tempos de avaliação, $p \leq 0.05$.

${ }^{*}$ Letras minúsculas diferentes representam diferença estatística intragrupo para os diferentes tempos de avaliação, $p \leq 0.05$.

\section{Análise Colorimétrica (CT)}

$\mathrm{O}$ teste ANOVA não detectou diferença entre os grupos $(\mathrm{p}=0,81)$. Os valores médios de $\Delta \mathrm{E}$ foram estatisticamente semelhantes para ambos os grupos: Controle (4.62 \pm 1.3$)$, Arginina 8\% (3.96 \pm 1.6$) \mathrm{e}$ Arginina $12 \%(4.79 \pm 3.0)$.

\section{DisCuSSÃo}

O aminoácido arginina pode promover a regeneração tecidual do esmalte ${ }^{22}$, e portanto, representa um benefício em potencial para o tratamento clareador ${ }^{23}$, dessa forma, dentifrícios contendo esse composto, vêm sendo empregados para prevenir e tratar a hiperssensibilidade dentinária ${ }^{24}$.

Frente à uma dissolução ácida, as moléculas de carbonato de cálcio dissolvem-se lentamente, provocando um aumento reacional de $\mathrm{pH}$, e os íons cálcio tornam-se biodisponíveis para promover a remineralização dentária ${ }^{5}$. Portanto, devido ao seu $\mathrm{pH}$ mais alcalino, o carbonato de cálcio é estabelecido como a fonte de cálcio preferencial para ser associada ao bioativo arginina ${ }^{25}$.

Imagens de alta resolução de microscopia eletrônica de varredura têm demonstrado que a oclusão dos túbulos dentinários pelo complexo arginina-carbonato de cálcio alcança uma profundidade de 2 micrômetros, não se limitando-se às áreas superficiais ${ }^{26}$.

Estudos têm relatado que a saliva in vivo ou in vitro é eficaz para remineralizar o esmalte e pode superar os efeitos adversos do clareamento ${ }^{28,29}$. Contudo, a remineralização pela saliva pode ser incompleta, deixando áreas susceptíveis à descalcificação e retenção de placa. Neste estudo, utilizou-se saliva artificial para simular as condições clínicas e padronizar as condições experimentais. De acordo com os resultados do presente estudo, o processo de remineralização no grupo controle, o qual foi mantido apenas em saliva, foi menos significativo que nos grupos experimentais (Arginina $8 \%$ e $12 \%$ ), demonstrando a eficácia da aplicação deste aminoácido na remineralização do esmalte.

A hipótese nula $\mathrm{H}_{01}$ foi aceita, uma vez que não houve diferença estatisticamente significativa de 
microdureza ao utilizar arginina em maior concentração. Entretanto, o grupo arginina $12 \%$ apresentou uma tendência de diferença. Sugere-se que o aumento da amostra, em estudos futuros, possa apontar esta diferença de modo significativo. A utilização do dentifrício contendo arginina e carbonato de cálcio pode aumentar a microdureza do esmalte através do carreamento gradual de íons de cálcio e fosfato para as superfícies de esmalte clareadas ${ }^{30}$.

O tratamento clareador, além de causar redução na quantidade disponível de minerais no esmalte, também pode provocar mudanças morfológicas neste tecido. $\mathrm{O}$ uso apenas de saliva não foi capaz de compensar a ação do peróxido de hidrogênio, havendo aumento significativo da rugosidade no grupo controle. A aplicação de arginina e carbonato de cálcio foi eficaz na redução deste efeito deletério, uma vez que ambos os grupos experimentais apresentaram resultados mais favoráveis que o grupo controle, entretanto a hipótese nula foi aceita, pois o aumento de concentração da arginina não acarretou diferenças significativas na rugosidade superficial, sugerindo-se que a concentração de $8 \%$ já se encontra no ponto de saturação do aminoácido estudado.

A hipótese $\mathrm{H}_{03}$ foi aceita, uma vez que não foram observadas diferenças significativas na variação de cor entre os grupos, constatando que a aplicação do bioativo arginina não influencia nos resultados do tratamento clareador. Receava-se que a utilização de dentifrícios à base do aminoácido arginina e carbonato de cálcio poderia influenciar na difusão do gel clareador devido ao seu modo de ação, o qual se baseia no mecanismo de oclusão dos túbulos dentinários ${ }^{1}$. A arginina, que é um aminoácido positivamente carregado, atua juntamente com o carbonato de cálcio, e liga-se à superfície dentinária negativamente carregada, para depositar um mineral semelhante à dentina dentro dos túbulos dentinários ${ }^{2}$. Contudo, a molécula de peróxido é muito pequena e pode penetrar nos espaços intersticiais entre os poros de esmalte ${ }^{8}$, o que provavelmente explica os resultados similares entre os grupos.

\section{Conclusão}

A aplicação de dentifrícios à base de arginina não interferiu no resultado do tratamento clareador e amenizou os efeitos deletérios resultantes da aplicação de peróxido de hidrogênio a $35 \%$, pois aumentou a microdureza e diminuiu a rugosidade superficial. $\mathrm{O}$ aumento da concentração deste agente remineralizante não gerou melhoras significativas.

\section{REFERÊNCIAS}

1. Joiner A. Tooth color: a review of the literature. J Dent. 2004; 32(Suppl 1):3-12.

2. Watts A, Addy M. Tooth discoloration and staining: a review of the literature. Br Den J. 2001 Mar; 190(6):30916.

3. Da Costa JB, McPharlin R, Paravina RD, Ferracane JL. Comparison of at-home and in-office tooth whitening using a novel shade guide. Oper Dent. 2010 Jul-Aug; 35(4):381-8

4. Polydorou A, Scheitza S, Spraul M, Vach C, Hellwig E. The effect of long-term use of tooth bleaching products on the human enamel surface. Odontol. 2017; 106 (1):6472.

5. Vieira-Junior W, Lima D, Tabchoury CPM, Ambrosano GMB, Aguiar FHB, Lovadino JR. Effect of toothpaste application prior to dental bleaching on whitening effectiveness and enamel properties. Oper Dent. 2016; 41(1):E29-E38

6. Fasanaro TS. Bleaching teeth: History, chemicals and methods used for common tooth discolorations. $J$ Esthet Dent. 1992 May-Jun; 4(3):71-8.

7. Bernardon JK, Ferrari P, Baratieri LN, Rauber GB. Comparison of treatment time versus patient satisfaction in at-home and in-office tooth bleaching therapy. $J$ Prosthet Dent. 2015; 114(6):826-30.

8. Thiesen CH, Rodrigues Filho R, Prates LHM, Sartori N. The influence of desensitizing dentifrices on pain induced by in-office bleaching. Braz Oral Res. 2013 Nov-Dec; 27(6):517-23.

9. Vaez SC,Faria e Silva AL, Loguercio AD, Fernandes MTG, Nahsan FPS. Preemptive use of etodolac on tooth 
sensitivity after in-office bleaching: a randomized clinical trial. J Appl Oral Sci. 2018; 26:1-9.

10. Goldberg M, Grootveld M, Lynch E. Undesirable and adverse effects of tooth-whitening products: a review. Clin Oral Investig. $2010 \mathrm{Feb}$; 14(1):1-10.

11. Sa Y, Sun L, Wang Z, Ma X, Liang S, Xing W, et al. Effects of two in-office bleaching agents with different ph on the structure of human enamel: an in situ and in vitro study. Clin Oral Invest. 2010 Jan-Feb; 14(1):1-10.

12. Basting RT, Rodrigues AL Jr, Serra MC. The effects of seven carbamide peroxide bleaching agents on enamel microhardness over time. J Am Dent Assoc. 2003 Oct; 134(10):1335-42

13. Cartagena AF, Parreiras SO, Loguercio AD, Reis A, Campanha, NH. In-office bleaching effects on the pulp flow and tooth sensitivity - case series. Braz Oral Res. 2015; 29(1):1-6.

14. Soares DG, Basso FG, Hebling J, de Souza Costa CA. Immediate and late analysis of dental pulp stem cells viability after indirect exposition to alternative in-office bleaching strategies. Clin Oral Investig. 2015 Jun; 19(5): 1013-20.

15. Cintra LTA, Benetti F, Ferreira LL, Gomes-Filho JE, Ervolino E, Gallinari M de O, et al. Penetration capacity, color alteration and biological response of two in-office bleaching protocols. Braz Dent J. 2016 Mar-Apr; 27(2): 169-75.

16. Roderjan, DA, Stanislawczuk R, Hebling J, Costa CA, Soares DG, Reis A. et al. Histopathological features of dental pulp tissue from bleached mandibular incisors. $J$ Mater Sci Eng B. 2014 Jan; 4(6):178-85.

17. Soares DG, Basso FG, Pontes, EC. Garcia, LDFR, Hebling J, De Souza Costa, CA. Effective toothbleaching protocols capable of reducing $\mathrm{H}_{2} \mathrm{O}_{2}$ diffusion through enamel and dentine. J Dent. 2014; 42(3): 351-8.

18. Hall C, Mason S, Cook J. Exploratory randomized controlled clinical study to evaluate the comparative efficacy of two occluding toothpastes - a 5\% calcium sodium phosphosilicate toothpaste and an $8 \%$ arginine/calcium carbonate toothpaste - for the longerterm relief of dentin hypersensitivity. J Dent. 2017; 60: 36-43.

19. West N, Seong J, Davies M. Dentine hypersensitivity. Oral Sci. 2014; 25: 108-22.

20. Cummins D. The efficacy of a new dentifrice containing $8.0 \%$ arginine, calcium carbonate, and $1450 \mathrm{ppm}$ fluoride in delivering instant and lasting relief of dentin hypersensitivity. J Clin Dent. 2009; 20(4): 109-14.
21. Huang Y, Duan Y, Qian Y, Huang R, Yang Z, Li Y, Zhou $Z$. Remineralization efficacy of a toothpaste containing $8 \%$ arginine and calcium carbonate on enamel surface. Am J Dent. 2013 Dec; 26(5):291-7.

22. Yesilyurt C, Sezer U, Ayar MK, Alp CK, Tasdemir T. The effect of a new calcium based agent, ProArgin, on the microhardness of bleached enamel surface. Aust Dent J . 2013 Jun; 58(2):207-12.

23. Docimo R, Perugia C, Bartolino M, Maturo P, Montesani L, Zhang YP, DeVizio W, Mateo LR, Dibart S Comparative evaluation of the efficacy of three commercially available toothpastes on dentin hypersensitivity reduction: an eight-week clinical study. J Clin Dent. 2011; 22(4):121-7

24. Lavender I, Petrou R, Heu MA, Stranick D, Cummins L, Kilpatrick L, et al. Mode of action studies on a new desensitizing dentifrice containing $8.0 \%$ arginine, a high cleaning calcium carbonate system and $1450 \mathrm{ppm}$ fluoride. Am J Dent. 2010; 14A-19A.

25. Cummins D. Dentin hypersensitivity: From diagnosis to a breakthrough therapy for everyday sensitivity relief. $J$ Clin Dent. 2009; 20(1):1-9.

26. Cintra LTA, Benetti F, Da Silva Facundo AC, Ferreira LL, Gomes-Filho JE, Ervolino E, et al. The number of bleaching sessions influences pulp tissue damage in rat teeth. J Endod. 2013 Dec; 39(12):1576-80

27. Smidt A, Feuerstein O, Topel M. Mechanical, morphologic, and chemical effects of carbamide peroxide bleaching agents on human enamel in situ.Quintessence Int. 2011 May; 42 (5):407-12.

28. Attin T, Schmidlin PR, Wegehaupt F, Wiegand A. Influence of study design on the impact of bleaching agents on dental enamel microhardness: a review. Dent Mater. 2009; Feb;25(2):143-57.

29. Markowitz K. A new treatment alternative for sensitive teeth: A desensitizing oral rinse. J Dent. 2013 Mar; 41(1):S1-11. 